\title{
What is the Hormonal Contraceptive Use Status
}

National Cancer Institute

\section{Source}

National Cancer Institute. What is the Hormonal Contraceptive Use Status. NCI

Thesaurus. Code C157410.

The current status of an individual with regards to contraceptive use. 